\title{
Contact Thermography in the Diagnosis of Childhood Migraine
}

\author{
Jörg R. Wolstein, Martin H. Reed, Shashi S. Seshia, P. Kubrakovich, B. Linsey and A. Samuel
}

\begin{abstract}
The objective of our prospective study was to assess the role of contact thermography in children with migraine. Contact thermograms were done in 54 children aged $4.2-16.5$ years (median 10.5 years), who were seen for headache and on 10 age-matched controls, between July and December 1991. Thermograms were interpreted as definitely normal, equivocally normal, equivocally abnormal, and definitely abnormal by a radiologist who was blinded to clinical information. Forty-eight children had the test between headaches; of these, four out of 26 patients (15\%) who had migraine without aura and 3 out of 14 children $(21 \%)$ who had migraine with aura had definitely abnormal thermograms. Nine out of 10 normal controls had definitely normal thermograms. The sensitivity of contact thermography in the diagnosis of childhood migraine, when done between headaches, was low in our study.
\end{abstract}

RÉSUMÉ: Thermographie de contact dans le diagnostic de la migraine chez l'enfant. Le but de notre étude prospective était d'évaluer le rôle de la thermographie de contact chez les enfants qui souffrent de migraine. Des thermogrammes de contact ont été faits chez 54 enfants âgés de 4.2 à 16.5 ans (médiane 10.5 ans), qui ont consulté pour céphalées, et chez 10 contrôles appariés pour l'âge, entre juillet et décembre 1991. Les thermogrammes étaient interprétés comme franchement normaux, douteux normaux, douteux anormaux et franchement anormaux par un radiologiste à qui l'information clinique n'était pas révélée. Quarante-huit enfants ont subi le test entre les céphalées; parmi eux, 4 des 26 patients (15\%) qui avaient des migraines sans aura et 3 des 14 enfants (21\%) de ceux qui avaient des migraines avec aura avaient des thermogrammes franchement anormaux. Neuf des 10 contrôles normaux avaient des thermogrammes franchement normaux. La sensibilité de la thermographie de contact dans le diagnostic de la migraine chez l'enfant, lorsque l'examen fait entre les céphalées, est faible dans notre étude.

Can. J. Neurol. Sci. 1993; 20:222-226

Migraine occurs in about $4-10 \%$ of all children,' migraine without aura (common migraine) being the most frequent type in this age group. ${ }^{2}$ The diagnosis of migraine is clinical and subjective. ${ }^{3,4}$ A test that minimizes subjectivity could be of value in situations where the history is in doubt, if precise diagnosis is required for epidemiological purposes or for selecting cases for testing the effect of specific medication.

Infrared thermography has been assessed in adults with recurrent headaches, thermograms being done between headaches in the majority. ${ }^{5-13}$ In adults, the highest incidence $(67-100 \%)^{8-10}$ of abnormal thermograms is in cluster headache, a type that is uncommon in children. ${ }^{14}$ Abnormalities on infrared thermograms have been found in $38-69 \% \%^{9,10}$ of adults with "common migraine" and in 56-75\%".10 of those with "classic migraine"; the authors did not state if their interpretation was done in a blinded fashion.

We have prospectively evaluated the role of contact thermography in the diagnosis of childhood migraine. To the best of our knowledge, this has not been done before.

\section{SuBJECTS AND MeThodS}

\section{Clinical Data}

The patients in the study were 54 children referred to the Pediatric Neurology Clinic of the Children's Hospital Winnipeg, between July and December 1991. They were seen by any one of four pediatric neurologists. The diagnosis was based on the clinical opinion of the individual neurologist; specifically, no attempt was made to force clinicians to classify a child's headache according to a fixed set of criteria. Clinical information was recorded on data sheets designed for the study. Our objective was to do thermograms both between (inter-headache) and during (intra-headache) headaches.

Twenty-three children from the community (not hospital based) were screened for the control group and ten were selected. Exclusion criteria were (i) evidence of systemic or neurologic dysfunction and (ii) a history of recurrent headaches either in the control or in $1^{\text {st }}$ or $2^{\text {nd }}$ degree relatives.

The study was approved by the Faculty Committee for the Use of Human Subjects in Research, Faculty of Medicine,

From the Sections of Pediatric Neurosciences (J.R.W., S.S.S.) and Pediatric Radiology (M.H.R., P.K., B.L., A.S.), Department of Pediatrics and Child Health, Children's Hospital and University of Manitoba, Winnipeg

Received September 21, 1992. Accepted in final form April 8, 1993

Presented in part at the XXVII ${ }^{\text {th }}$ Canadian Congress of Neurological Sciences, June 25-28, 1992, Winnipeg, Canada

Reprint requests to: S.S. Seshia, M.D., Section of Pediatric Neurosciences, University of Manitoba and Children's Hospital, AE-208 840 Sherbrook Street, Winnipeg, Manitoba, Canada R3A IS1 
University of Manitoba, Winnipeg. Informed consent was obtained.

\section{Technical Methods}

Thermography was done using the Flexi-Therm ${ }^{\circledR}$ System (Flexi-Therm Inc., Westbury, N.Y. USA). The system consists of flexible reusable contact detectors that change color according to temperature. The detectors have a temperature range from $18^{\circ} \mathrm{C}-40^{\circ} \mathrm{C}$. Each detector has a specific temperature range and there is a temperature range overlap between detectors; e.g., the detector labelled " $\# 33$ " has a range from $30.0^{\circ} \mathrm{C}$ to $35^{\circ} \mathrm{C}$, whilst the one labelled " $\# 32$ " has a range from $28.9^{\circ} \mathrm{C}$ to $33.5^{\circ} \mathrm{C}$. A temperature based color scale is attached to each detector. There are 6 individual temperature-dependent colors on each detector. Each color merges into the next and hence intermediate colors can also occur. Colors are detector specific but not temperature specific; e.g., a skin temperature of $32^{\circ} \mathrm{C}$ corresponds to "yellow" on the "\#33" detector but to green on the "\#32" detector. A complete colorstep reflects a temperature difference of $0.5^{\circ} \mathrm{C}$ $1^{\circ} \mathrm{C}$, depending on the detector used.

The procedure was standardized. Thermography was performed in a draft-free room with a controlled room temperature of $21^{\circ}-23^{\circ} \mathrm{C}$. There was a 15 minute adapting time to room temperature for each patient; the face and temples were kept completely exposed. Frontal and temporal areas of the head were tested. The frontal area included the nose and the forehead up to the lateral aspect of the orbits. Thermograms were done at least twice at 5 - 10 minute intervals using detectors with different temperature ranges. Images were photographed, after they had reached thermal equilibrium.

\section{Interpretation of Thermograms}

All thermograms were interpreted by a pediatric radiologist, who was blinded to clinical information. A thermogram was considered to be normal if there was no difference in temperature between right and left sides of forehead and temples. A thermogram was considered to be definitely abnormal, (i) if there was a temperature difference of more than $0.5^{\circ} \mathrm{C}$ between the left and right sides of the forehead or the left and right temples, or (ii) if there was a circumscribed "cold patch" as defined in the literature. ${ }^{10}$ The radiologist interpreted thermograms as definitely normal, definitely abnormal, equivocally normal, or equivocally abnormal; the last two categories reflected the radiologist's uncertainty about a thermographic finding being normal or abnormal. Thermographic findings had to be consistent on recordings done with different detectors.

\section{ReSULTS}

\section{General Features}

The ages of the 54 patients ranged from 4.2 to 16.5 years (median of 10.5 years). The ages of the 10 control subjects ranged from 6.2 to 13.2 years (median 10.2 years). The patient group had 21 boys and 33 girls and the control group 5 boys and 5 girls. At the time of the study, five children were on prophylactic treatment for migraine and two children were on anti-convulsants. All patients were then clinically followed up for two to seventeen months (median six months). The clinical diagnosis did not change in 53 of 54 children. In one child, the clinical diagnosis changed from "combination of migraine and tensiontype headache" to "migraine" alone.

\section{Inter-headache Thermograms}

The results are summarized in Table 1. Fifty-one of 54 patients had a thermogram done between headaches at the first visit. Thermograms were technically unsatisfactory in three of the 51 patients. Of the remaining 48 subjects, inter-headache thermograms were definitely abnormal in four (15\%) of 26 children who had migraine without aura and in three $(21 \%)$ of 14 children who had migraine with aura.

\section{Intra-headache Thermograms}

Five of 54 children had a thermogram done during a headache (Table 1). One of these five children had a definitely abnormal thermogram (clinical diagnosis: ophthalmoplegic migraine). She did not have an inter-headache thermogram.

Table 1. Results of Thermograms

\begin{tabular}{lccc}
\hline \hline Subject Group & Normal & Abnormal \\
& definitely & equivocally & definitely \\
equivocally
\end{tabular}

\section{PATIENTS \\ (test between headaches) \\ Migraine \\ without aura \\ with aura \\ paroxysmal vertigo \\ Migraine \& Tension-type \\ Secondary}

\author{
PATIENTS \\ (test during headache) \\ Migraine \\ ophthalmoplegic \\ Migraine \& Tension-type \\ Tension-type
}

14
8
4
1

$\begin{array}{ccc}4 & 6 & 26 \\ 3 & - & 14 \\ - & - & 1 \\ - & 1 & 6 \\ - & - & 1\end{array}$




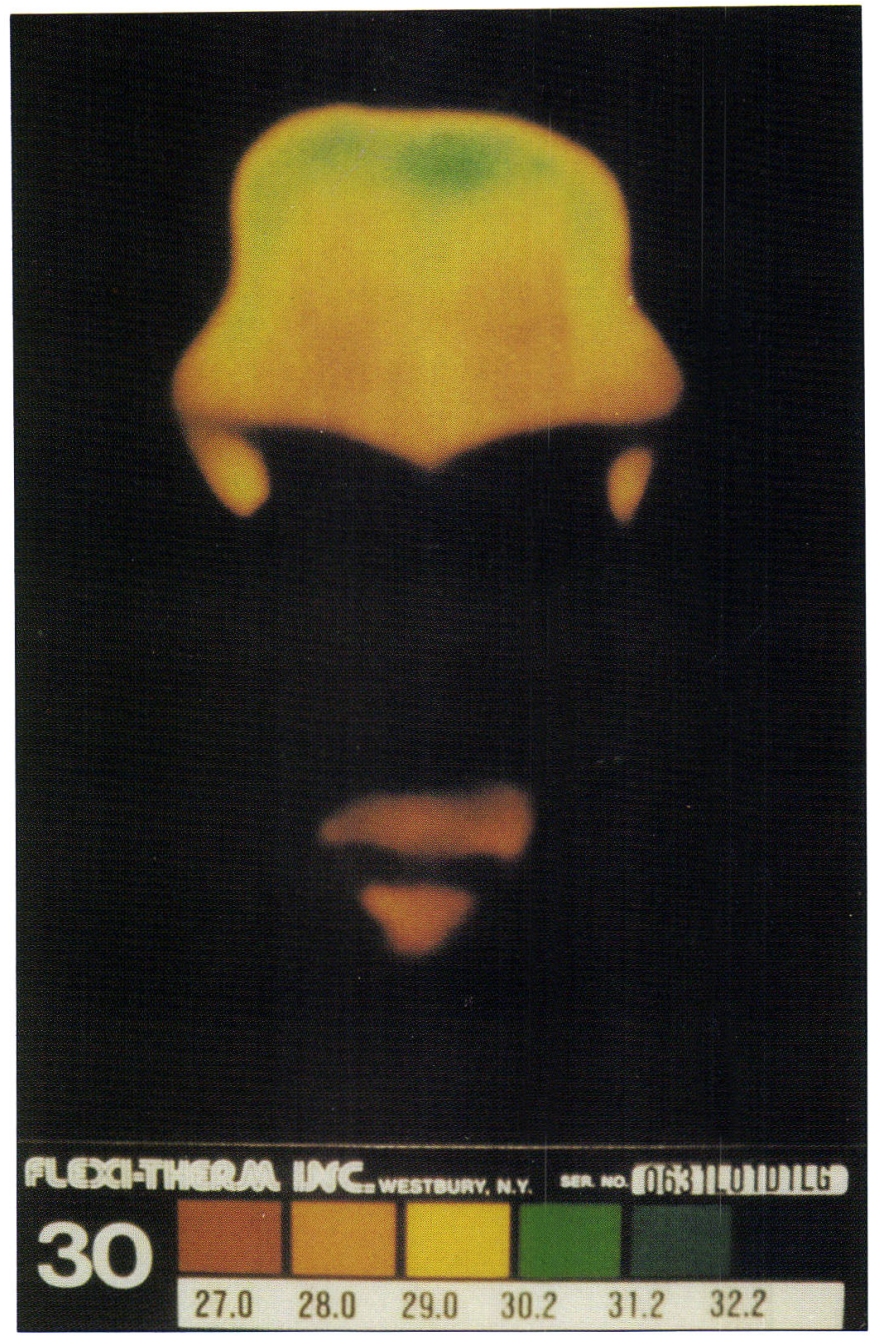

Figure I - Normal thermogram of face and nose (anterior view) obtained by using a detector with a range from $27.0^{\circ} \mathrm{C} \cdot 32.2^{\circ} \mathrm{C}$. With this detector, the yellow color reflects a temperature of $29.0^{\circ} \mathrm{C}$, whilst green reflects a temperature of $30.2^{\circ} \mathrm{C}$. There is symmetry between the right and left sides of the forehead.

Both intra- and inter-headache thermograms were normal in two children who had a combination of migraine and tension-type headache. All intra-headache thermograms were done more than six hours after the onset of the headache.

\section{Control Thermograms}

Nine of ten controls had definitely normal thermograms. The one control subject, who had a definitely abnormal thermogram, has a sister who developed one episode of headache with visual disturbance after the study was done.

Examples of normal and abnormal thermograms are shown in Figures 1 and 2.

\section{Discussion}

In our study, contact thermograms done between headaches were definitely abnormal in four out of 26 children (15\%) who had migraine without aura and three out of 14 children $(21 \%)$ who had migraine with aura.

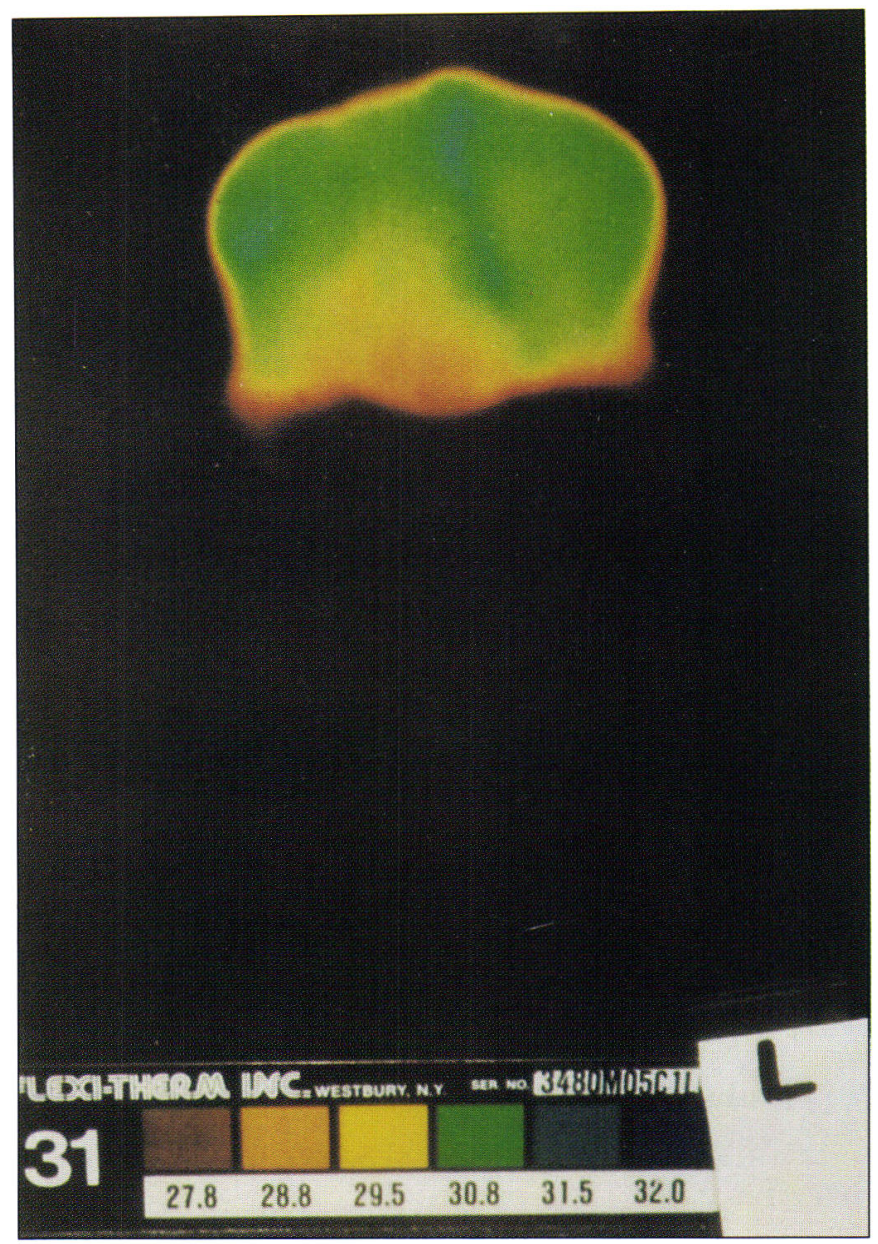

Figure 2 - Abnornal thermogram of face and nose (anterior view) showing an area of decreased temperature (cold patch, yellow colour) over the patient's right supraorbital and fromtal regions. With this detector, the yellow color reflects a temperature of $29.5^{\circ} \mathrm{C}$, whilst green reflects a temperature of $30.8^{\circ} \mathrm{C}$. There is asymmetry between the right and left sides of the forehead. Temperature range of detector: $27.8^{\circ} \mathrm{C}-32.0^{\circ} \mathrm{C}$.

The interpretation of thermograms, like the interpretation of most radiological tests, is qualitative and can be influenced by intra- and inter-observer variability. We minimized bias by blinding the radiologist to clinical data. We are unsure if other thermographic studies on migraine used the same approach.

We enhanced consistency by doing thermograms on at least two occasions with time intervals of $5-10$ minutes. This reduced the probability of an abnormality being caused by a temporary temperature change. Also, we used at least two detectors with different temperature ranges and therefore different temperature-related color scales. Hence, abnormalities would be shown in different colors, minimizing interpretation bias. Thermograms were considered abnormal only if the findings were present on studies done with more than one detector.

Thermograms (i) were abnormal in $18 \%$ and $13 \%$ of adults with muscle contraction headache, ${ }^{10.11}$ which corresponds to tensiontype headache according to the 1988 classification of the International Headache Society (IHS) ${ }^{15}$ and (ii) showed 
temperature asymmetries in $7 \%$ and $22 \%$ of adult controls in two separate studies; ${ }^{10.11}$ the authors did not provide an explanation for the abnormal findings.

Our criteria for selecting normal controls were stricter than those in most previous studies, because we excluded subjects with recurrent headaches and those who had a $1^{\text {st }}$ or $2^{\text {nd }}$ degree relative with recurrent headaches. Despite this, one of our 10 carefully selected controls had an abnormal thermogram. She has a sibling, who subsequently developed an episode that, whilst consistent with migraine with aura, does not meet IHS criteria, because it is an only attack. We speculate that our control subject with the abnormal thermogram may have a predisposition to migraine. Martyn has drawn attention to the challenges encountered in choosing control subjects for neurologic research. ${ }^{16}$

Our criteria for considering thermograms as abnormal (cold patch; temperature asymmetries) are similar to those in the literature. However, we interpreted thermograms as definitely normal, equivocally normal, definitely abnormal or equivocally abnormal to avoid forced classification into just normal or abnormal. Recently, Hubbard has cautioned against a rigid normal-abnormal reporting format and emphasized the importance of also reporting subtle, non-specific or borderline findings when interpreting thermograms. ${ }^{17}$ Hence, differences in reporting format may also explain differences in results between centers.

Thermograms on five children ( 3 with migraine, 1 with migraine and tension-type headache, 1 control) showed unilateral or bilateral paramedian streaks of increased temperature without any other abnormality. We felt that such streaks could be caused by an underlying vein and therefore represent a normal finding. However, we recognize the finding may have been due to vascular dysfunction. Such streaks isolated to the paramedian region have not been described previously. We did not consider them to be a "Chai" sign, ${ }^{9}$ because streaks in the temporal part of the forehead were not present.

The majority of thermograms in our study, as in previous studies, were done between headaches, because most parents found it inconvenient to come to the hospital when their child had a typical headache. There is little information in the literature about the relative sensitivity and specificity of inter- compared to intra-headache thermography in migraine and tensiontype headache. Drummond and Lance $^{6}$ found a statistically significant difference $(\mathrm{p}<0.05)$ between the orbital temperature on inter-headache $\left(35.4^{\circ} \mathrm{C}\right)$ and intra-headache thermograms $\left(35.6^{\circ} \mathrm{C}\right)$ in 52 adult migraineurs. However, there was no statistical difference when the fronto-temporal regions were tested in these patients, the average temperature measurements being $34.4^{\circ} \mathrm{C}$ and $34.5^{\circ} \mathrm{C}$ in inter- and intra-headache thermograms respectively. Inter-test temperature variability among normal subjects was not assessed.

Drummond and Lance $^{6}$ did not find a correlation between the side of thermographic abnormality and the location of unilateral migraine headache. We speculate that abnormalities in migraineurs may be bilateral and include face and head. For this reason, a reference point away from the face and head would be ideal, but none has been described in the literature. The situation is analogous to the absence of an ideal reference site in electroencephalography. Presently, recognition of abnormalities on thermograms is based on identifying differences in temperature pattern between (i) a circumscribed area and its surrounding region or (ii) left and right sides. Consequently, the test may be misinterpreted as normal, if the abnormal pattern is diffuse or bilateral.

The lower incidence of abnormal thermograms in our study may be due to several factors: (i) Contact thermography may not be as sensitive as infrared thermography; however the Committee on Quality Control and Qualifications of the American Academy of Thermology states ${ }^{18}$ that either method "provides comparable, reliable data", (ii) there may be interobserver (inter-center) variability in performing and interpreting thermograms, specially if interpretation is not blinded, and (iii) the phenomena that underlie the thermographic abnormalities may be different in children with migraine as compared to adult migraineurs.

We used contact thermography, whilst published studies have been on infrared thermography. We are unaware of any study comparing the sensitivity of infrared and contact thermography in migraine. Contact thermography detectors are easy to handle and the process is simple to explain to children. In our experience, even young children tolerate the method well. Infrared thermography equipment is much more expensive than contact thermography equipment.

Our study design mimicked the clinical setting, since no attempt was made to force the clinician to diagnose headaches according to a fixed set of criteria.

Our study may have several possible shortcomings: (i) firstly, given the high incidence of headache in the general population, the number of subjects is relatively small, (ii) secondly, although we used standardized data sheets to enhance consistency, we did not study inter-observer variability between the pediatric neurologists in typing headache, (iii) thirdly, we did not select patients using IHS criteria; ${ }^{15}$ these criteria have not been uniformly accepted in pediatric practice. However, the clinical diagnosis was essentially unchanged in the study population in the course of follow-up, two to seventeen months after testing. Furthermore, in a concurrent study, there was $86 \%$ agreement at the one digit level between the clinical diagnosis on 36 children with headache made by the four pediatric neurologists who referred patients for thermography and the diagnosis on the same children made by an independent physician using IHS criteria, ${ }^{19}$ and (iv) fourthly, we have not tested intra-observer variability in the interpretation of the thermograms, although interpretation was blinded. There have been similar shortcomings in previous thermographic studies on migraineurs. The clinical impression remains the gold standard for diagnosis in all studies.

Only $17 \%$ of all migraineurs in our study had a definitely abnormal thermogram, a percentage that is not high enough to consider using contact thermography as a standard screening procedure in children with headache.

Until data to the contrary emerge, the report of the American Academy of Neurology on infrared thermography in neurologic practice, which states that (infrared) "thermography has not been shown to provide sufficient reliable characterizing information about neurologic dysfunction ... for the clinical diagnosis of ... headache", ${ }^{20}$ likely also applies to contact thermography.

\section{ACKNOWLEDGEMENTS}

We thank Drs. C. Adams, F. Booth and J. Reggin for their participation. The study was funded by a Harry Medovy Fellowship (to JW) and the Children's Hospital of Winnipeg Research Foundation (CHWRF). 
Note

References were retrieved from several sources including MEDLINE (1985-1992) and the International Bibliography of Medical Thermography, ${ }^{21}$ which was published in 1987 (to our knowledge, a more recent Bibliography has not been published).

\section{REFERENCES}

1. Hockaday J. Definitions, clinical features, and diagnosis of childhood migraine. In: Hockaday J, ed. Migraine in Childhood. London: Butterworths, 1988: 5-24.

2. Rothner AD. Headaches in children: a review. Headache 1978; 18 : 169-175.

3. Edmeads J. Is thermography a marker for vascular headache? (editorial) Headache 1986; 26: 47.

4. Barlow CF. Headaches and migraine in childhood. Clinics in Developmental Medicine, no 91. Oxford: Spastics International Medical Publications, Blackwell Scientific, 1984: 10-13, 56.

5. Lance JW, Anthony M. Thermographic studies in vascular headache. Med J Aust 1971; 1: 240-243.

6. Drummond PD, Lance JW. Facial temperature in migraine, tensionvascular and tension headache. Cephalalgia 1984; 4: 149-158.

7. Swerdlow B, Dieter JN. The persistent migraine "cold patch" and the fixed facial thermogram. Thermology 1986; $2: 16-20$.

8. Drummond PD, Lance JW. Thermographic changes in cluster headache. Neurology 1984; 34: 1292-1298.

9. Kudrow L. A distinctive facial thermographic pattern in cluster headache - the "Chai" sign. Headache 1985; 25: 33-36.

10. Swerdlow B, Dieter JN. The validity of the vascular "cold patch" in the diagnosis of chronic headache. Headache 1986; 26: 22-26.
11. Mathew N, Alvarez L. The usefulness of thermography in headache. In: Rose FC. Progress in Migraine Research. London: Pittman, 1984, 232-245.

12. Swerdlow B, Dieter JN. The vascular "cold patch" is not a prognostic index for headache. Headache 1989; 29: 562-568.

13. Dalla Volta G, Anzola GP, DiMonda V. The disappearance of the "cold patch" in recovered migraine patients: thermographic find. ings. Headache 1991; 31: 305-309.

14. Maytal J, Lipton RB, Solomon S, Shinnar S. Childhood onset cluster headaches. Headache 1992; 32: 275-279.

15. Headache Classification Committee of the International Headache Society. Classification and diagnostic criteria for headache disorders, cranial neuralgias and facial pain. Cephalalgia 1988;8 (Suppl 7): 1-96.

16. Martyn $\mathrm{CN}$. Choosing cases and controls in neurological research. J Neurol Neurosurg Psychiatry 1990; 53: 453-454.

17. Hubbard JE. Thermography (correspondence). Neurology, 1992: 42: $700-701$.

18. Committee on Quality Control and Qualifications of the American Academy of Thermology. Technical Guidelines, edition 2. Thermology 1986; 2: 108-112.

19. Wolstein J, Booth F, Reggin J, Seshia SS. Diagnosis of childhood headache by International Headache Society criteria. (abstract) Can J Neurol Sci 1992; 19: 308

20. American Academy of Neurology, Therapeutics and Technology Assessment Subcommittee. Assessment: thermography in neurologic practice. Neurology 1990; 40: 523-524.

21. Abernathy M, Abernathy TB. International bibliography of medical thermography. Thermology 1987; 2: 118-533. 